\title{
Transmission Line Galloping Prediction Based on Numerical Weather Prediction Results
}

\author{
Li Shuai ${ }^{1}$, Li Zhe ${ }^{2}$, Liang Yun ${ }^{2}$, Liu Shanfeng ${ }^{2}$ \\ ${ }^{1}$ Henan EPRI Hitech Group Co., Ltd., Zhengzhou, China \\ ${ }^{2}$ State Grid Henan Electric Power Research Institute, Zhengzhou, China
}

Email address:

lishuai8363@163.com (Li Shuai),123875689@qq.com (Liang Yun)

\section{To cite this article:}

Li Shuai, Li Zhe, Liang Yun, Liu Shanfeng. Transmission Line Galloping Prediction Based on Numerical Weather Prediction Results. Journal of Electrical and Electronic Engineering. Vol. 6, No. 5, 2018, pp. 135-141. doi: 10.11648/j.jeee.20180605.13

Received: November 2, 2018; Accepted: December 3, 2018; Published: December 11, 2018

\begin{abstract}
With the expansion and extension of power grid scale, the impact of catastrophic weather on the safe operation of power grids is increasing, and strengthening the prediction and early warning of catastrophic weather processes, which have a serious impact on power grid production, can effectively improve the efficiency and ability of power grids to cope with catastrophic weather. In this paper, using multi-data source data processing technology, the monitoring data of the transmission line micro-meteorological monitoring device is applied to the refinement numerical prediction calculation to improve the accuracy of the numerical weather forecast results in Henan province, and based on this research to establish the transmission line dance Prediction model, Predict the occurrence probability of transmission line dance under different meteorological environment conditions. Through the fine regional numerical prediction system and dynamic reduction scale technology, the hourly meteorological factor forecast of $1 \mathrm{~km}$ resolution in Henan Province in the next 3 days is predicted, the statistical revision of the forecast field of meteorological elements around the transmission line is established, and based on this, the prediction model of transmission line dance can greatly improve the prediction accuracy of transmission line dance, To form a more precise and accurate dance prediction results, to facilitate the power sector to carry out different time scales of transmission line dance early warning work.
\end{abstract}

Keywords: Multiple Data Source, Dynamical Downscaling, Numerical Prediction, Galloping Prediction Model, Probability of Galloping

\section{Introduction}

As the scale of the power grid continues to expand, The influence of overhead transmission lines on severe meteorological conditions is becoming more obvious. Especially every November-the following March, Affected by the snow and rain, the north of Heilongjiang, south to Hunan, the vast area of the transmission line in specific meteorological conditions will occur dancing phenomenon [1], A serious threat to the safe operation of the equipment and the grid.

The galloping of overhead transmission lines is a phenomenon of aerodynamic instability, It is a self-excited vibration phenomenon of low frequency $(0.1 \sim 3 \mathrm{~Hz})$ and large amplitude (20 300 times of conductor diameter) caused by uneven ice-covering of transmission lines under the action of wind, In vibrational form, there are only 1 or a few half-waves within a stall [2]. The occurrence of the dancing event can cause the electrical insulation breakdown trip of the line, but also may cause the disconnection, the transverse damage, the inverted tower and so on difficult to recover directly the accident, has brought the great threat to the transmission line and the power grid safe operation.

In recent years, we have carried out a lot of research and application of dance monitoring and control technology in the course of reducing the harm caused by dancing to the line body and the power grid operation [3], and have achieved good results by applying it in production. Over the years, the research results show that the 3 important factors that cause dancing are the conductor icing, wind excitation, line structure and parameters [4], Under the condition that the structure and parameters of transmission lines are fixed, the occurrence of wire dancing events is affected only by the 
external factors such as wind speed, wind direction, angle of conductor axis, temperature and relative humidity, etc. [5], Therefore, how to improve the accuracy of meteorological forecast results is the focus of improving dancing monitoring and early warning. This paper mainly studies the prediction technology of line dancing based on the results of fine numerical weather forecast, and finally gives the probability of the occurrence of line dancing in different regions under specific meteorological conditions, provides the necessary information support for adjusting the operation mode of the power grid, allocating emergency materials, and making the plan of looting (checking) to achieve early warning, early precaution and harm reduction.

\section{Data Preprocessing Technology for Multi-Data Sources}

In order to make more fine and accurate forecast products of meteorological elements along the transmission lines of Henan power grid and to facilitate the early warning work of power meteorological disasters at different time scales in the power sector, the research and development and application of data preprocessing technology for multi-data sources are carried out in the following 4 steps.

(1) Through the fine regional numerical prediction system, the hourly weather element forecast for the next 3 days covering the $9 \mathrm{~km}$ resolution of Henan province is obtained.

(2) Based on the forecast of the province, the forecast of hourly meteorological elements of $1 \mathrm{~km}$ resolution in the next
3 days is obtained by using the Power drop scale technology.

(3) Aiming at the forecast factors such as wind speed, temperature and humidity, the revised model of forecast product is established, and the forecast field of meteorological elements around the line is revised statistically, and more accurate factor forecast field is obtained.

(4) Using the data of automatic station in Henan Province, the basic background forecast field is improved, and then the extrapolation forecast is carried out to further improve the prediction accuracy.

\section{Application of Refined Numerical Prediction Technology}

\subsection{Introduction of Refined Numerical Prediction Technology}

The numerical prediction is based on the refined regional numerical prediction System (BJRUCV3.0), which is developed on the basis of mesoscale meteorological model (Weather research FORECAST, WRF). The WRF model system is a new generation mesoscale forecasting model and assimilation system that the American research departments and universities participate in the research and development [6]. The forecast system has a horizontal resolution of $9 \mathrm{~km}$, horizontal grid points of $400 \times 649$, vertical 50 layers, the specific calculation of the forecast flow as shown in Figure 1.

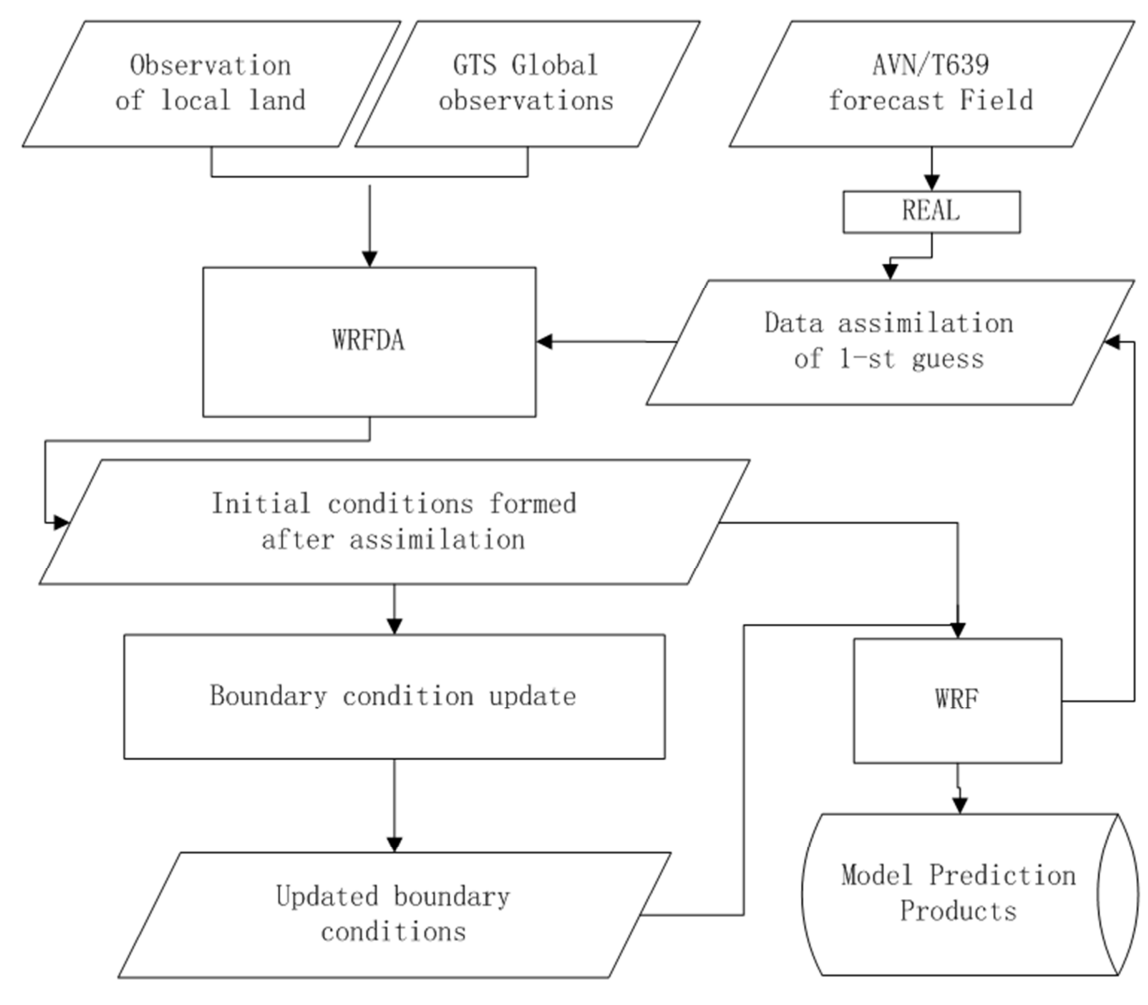

Figure 1. Flow chart of BJRUCv3.0 forecast system.

Production of horizontal resolution in Henan region based on BJRUCv3.0 forecast system 9 miles The forecast result of 
ground meteorological elements in the next 3 days hourly basis, the forecast elements and the time limitation as shown in table 1 , the numerical prediction region is shown in Figure 2.

Table 1. Numerical weather prediction elements and aging schedule at $9 \mathrm{~km}$ resolution.

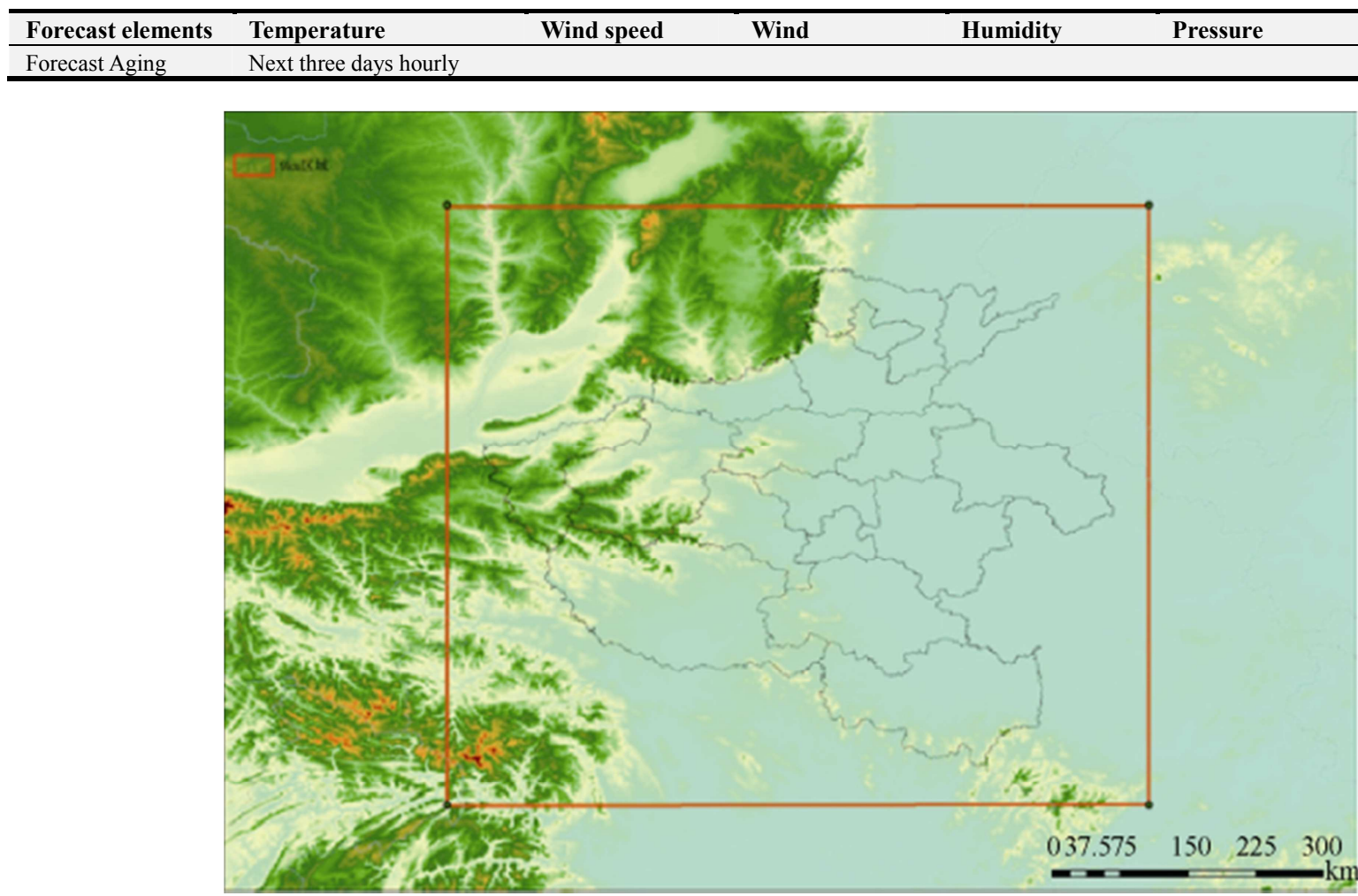

Figure 2. Numerical weather forecast area at $9 \mathrm{~km}$ resolution in Henan area.

\subsection{Calibration of Numerical Weather Forecast Results}

In order to understand the performance of the regional numerical prediction products, this paper chooses hourly output of the future $\mathrm{H}$ forecast products from July 1, 2014 to January 31,2015 for the data to be tested, the live observation data selects the hourly observations of 119 national meteorological stations in Henan province, and tests the variables for the ground average wind speed, Relative humidity, temperature and precipitation. Continuous variables (wind speed, relative humidity, and temperature) are tested using classical statistical methods, including deviation test (BIAS) and root mean square error (RMSE) analysis, wherein:

$$
\begin{aligned}
B_{\mathrm{IAS}} & =\sum_{i=1}^{N}\left(V_{\mathrm{obs}, i}-V_{\mathrm{model}, i}\right) / N \\
R_{\mathrm{MSE}} & =\sqrt{\frac{\sum_{i=1}^{N}\left(V_{\mathrm{obs}, i}-V_{\text {model }, i}\right)^{2}}{N}}
\end{aligned}
$$

In the formula: Vobs, $\mathrm{i}$ is the variable observation value; Vmodel, $i$ is the model value.

After a systematic examination of the model product, the project team concludes the following two categories:
1) The forecast effect of temperature and relative humidity is good, and the forecast error increases with the increase of the forecast time. In space, the forecast error is relatively large in northwest of Henan province.

2) The wind speed forecast has obvious systematic and large characteristics, and the daytime error is large, the night deviation is small, and the wind speed forecast error is large in the complicated terrain area.

\subsection{Descending Scale of Key Area}

The microscale model (CALMET) is used for the reduction of scale prediction. Calmet model is a grid of complex terrain wind field dynamic diagnosis model recommended by the United States Environmental Protection Agency (EPA), which uses the principle of mass conservation to diagnose the dynamic force of wind field, mainly considering the dynamic effect of terrain on the atmosphere near the formation, the generation of slope airflow and the obstacle blocking effect, Three-dimensional non-divergence treatment is used to eliminate the false fluctuation caused by interpolation.

Based on the background prediction field of $9 \mathrm{~km}$ resolution in Henan province, using Calmet model to calculate the dynamic descending scale of two key experimental areas, the forecast results of $1 \mathrm{~km}$ of the key region horizontal resolution are generated, and the forecast elements are shown in table 2. 
Key Region selection basis: Based on the distribution characteristics of power grids in Henan province, the selection of two key descending scale calculation regions in the area of meteorological disaster prone areas is shown in Figure 3. The area 1 grid points are $201 \times 161$, and the area 2 grid points are $241 \times 161$.

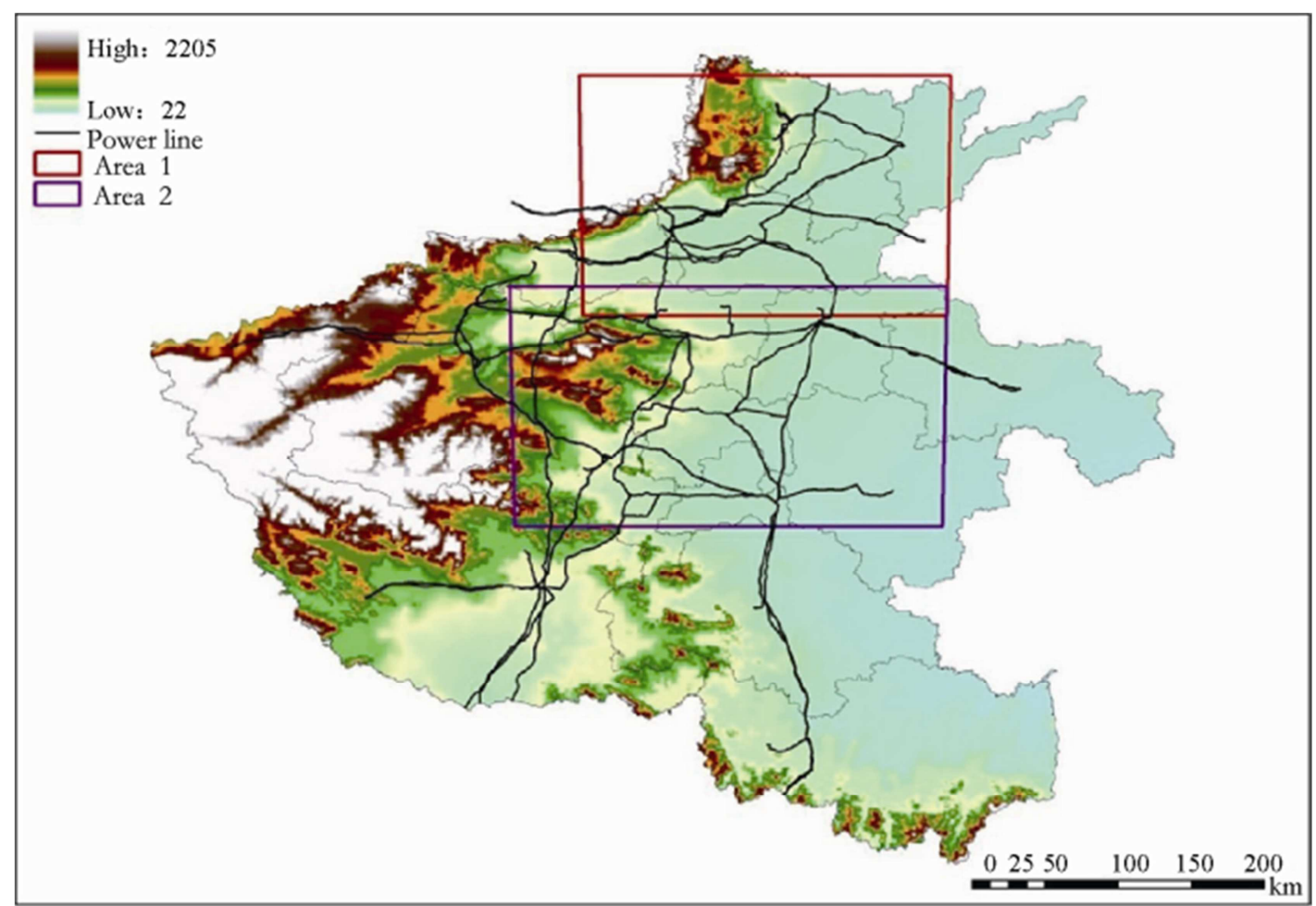

Figure 3. Schematic diagram of the key areas for downscaling in Henan.

Table 2. Numerical weather prediction elements and aging schedule at $1 \mathrm{~km}$ resolution in key areas.

\begin{tabular}{lll}
\hline Forecast elements & Forecast height & Forecast Aging \\
\hline Temperature & & \\
Wind speed & & \\
Wind & & \\
Humidity & $10,30,50$ and $70 \mathrm{~m}$ & Next three days hourly \\
Pressure & & \\
Precipitation & & \\
Sleet & & \\
\hline
\end{tabular}

Figure 4 is an example of the 10 and a $1 \mathrm{~m}$ height horizontal wind speed prediction field in the Henan power grid's key scale-down zone. It can be clearly seen from the figure that the wind speed distribution of the 10 and the $\mathrm{m}$ height is significantly different, compared to the $9 \mathrm{~km}$ forecast wind field is more refined, the application is more valuable.

\section{Establishment of Transmission Line Galloping Prediction Model}

The model of transmission line dancing early warning is based on the factual information and forecast information of meteorological disaster characteristic parameters provided by each meteorological observatory (station) in Henan Province, comprehensively calculates and deals with the meteorological forecast data and the geographical location information (GIS) of the transmission line, and gives the meteorological disaster risk analysis of the transmission line in the area, In the case of severe meteorological conditions, the fault risk line is given the corresponding warning information (warning number, release time, warning level, line or section information, etc.) to realize scientific transmission line galloping disaster risk warning.

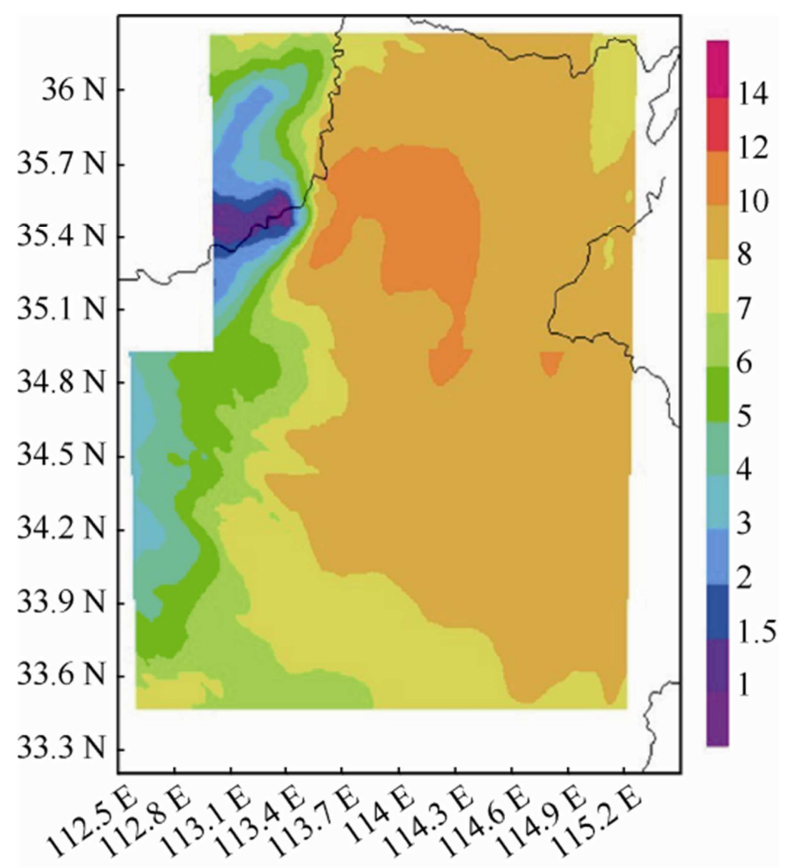

(a) $10 \mathrm{~m}$ height 


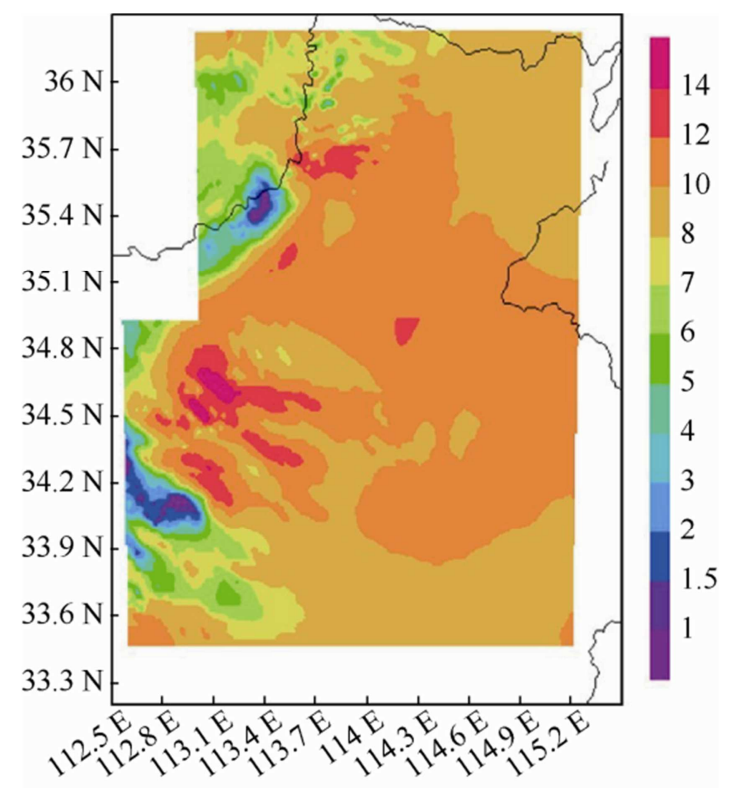

(b) $70 \mathrm{~m}$ height

Figure 4. Results of horizontal wind speed forecasting at a height of $10 \mathrm{~m}$ and $70 \mathrm{~m}$ in Henan.

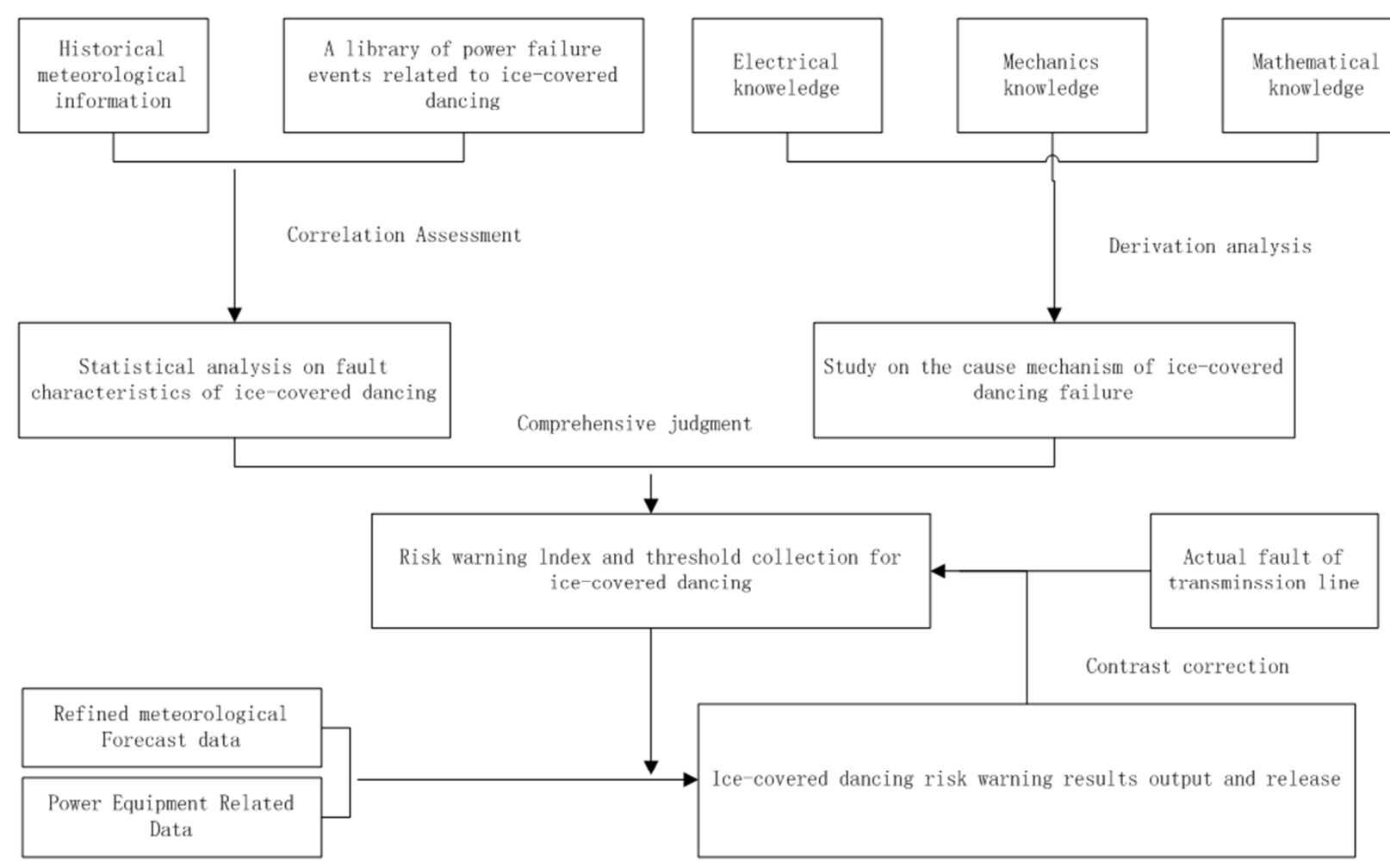

Figure 5. Process of early warming of ice-coating galloping.

\subsection{Prediction Model of Transmission Line Galloping}

The formation of wire dancing is inseparable from the external meteorological environment, including wind speed, wind direction angle to the traverse axis, temperature and relative humidity. The internal cause of wire dancing is the route structure and parameters, and when the internal causes are relatively constant, the change of things is determined by external factors [7]. Therefore, the model first combined with

\subsection{Basic Modeling Ideas and Methods}

In this paper, the basic modeling method combining mechanism research and statistical analysis is used: in the extraction of early warning feature parameters, the meteorological disaster with clear and thorough data and information, and the method of mechanism research are used to extract the early warning characteristic value, and the mechanism of transmission line fault caused by meteorological conditions is more complicated. Or some of the parameters difficult to obtain meteorological disaster, using statistical analysis method to extract the early warning characteristic value, in the selection of early warning threshold value, using the P-Division method, fault histogram peak-valley method, the actual fault event of the power grid and the meteorological characteristics of the threshold value selection method. By determining the characteristic value and threshold value of the early warning, and then inputting the refined meteorological forecast data, we can obtain the corresponding warning result of the network meteorological correlation risk. The alert process is shown in Figure 5. 
Table 3. Internal cause classification statistics for conductor galloping.

\begin{tabular}{lll}
\hline Wire structure & Wire cross section $\boldsymbol{S} / \mathbf{m m}$ & Gear distance $\boldsymbol{L} / \mathbf{m}$ \\
\hline Single Wire & $\operatorname{Small}(S \leq 150)$ & $\operatorname{Small}(L \leq 300)$ \\
Split Wire & $\operatorname{Middle}(150<S \leq 300)$ & $\operatorname{Middle}(300<L \leq 600)$ \\
- & $\operatorname{Big}(S>300)$ & $\operatorname{Big}(L>600)$ \\
\hline
\end{tabular}

A training sample set is constituted by the historical meteorological characteristic data record under the condition of the dancing of a certain type of transmission line, and a strong classifier is formed by using the Gini index-based decision pile as weak classifier and the Adaptive Enhancement Algorithm (adaptive boosting, adaboost). And then with the forecast data of the weather characteristic vector of the dancing correlation $\mathrm{x}$ as the input, we can get the forecast result of the line's dancing in the Forecast meteorological environment Y (1 means the prediction of the dance, -1 means that the prediction does not occur). In addition, the following formula is used to calculate the confidence of the result (probability):

$$
P(\boldsymbol{x}, y)=\frac{\sum_{t} a_{t} C_{t}(\boldsymbol{x})}{\sum_{t}\left|a_{t}\right|}
$$

In the formula: $\mathrm{CT}$ is weak classifier; at is a weak classifier factor. $\mathrm{P} \in[-1,+1]$, a large positive (negative) boundary indicates that the confidence of the line to occur (does not occur) is high, and the smaller boundary indicates a low confidence in the predicted result, such as $\mathrm{p}=0.9$, which indicates that the conductor is likely to dance.

\section{Application of Transmission Line Galloping Prediction Model}

In the form of grid GIS map, the latest system calculation and release of icing, dance prediction range, distribution, impact line and so on, according to the dance probability is divided into 4 grades, and in different colors to display. In the form of a list of the current day system calculation and release of icing, dance prediction release time, maximum icing thickness, maximum dancing probability, impact area, etc., and provide history query and positioning function.

November 2015 22-24th, the model successfully predicted the large area transmission lines in South Henan and North Henan Province, and timely release of forecast information for the emergency repair of the power grid to buy valuable time. Dance model application So far, the system has issued a high probability of dance warning 296 times, send early warning SMS 758. On the basis of improving the level of early warning and equipment maintenance and management, the total reduction of the fixed assets loss of power grid equipment and the cost of emergency maintenance are about 22.2 million yuan; and greatly improve the reliability of the power grid operation.

\section{Conclusion}

This paper mainly introduces the meteorological basis data, using multi-data processing technology, through the fine regional numerical prediction system and the dynamic scale-down technology to obtain more accurate hourly meteorological element forecast, and based on this, the transmission line galloping Prediction model is established, which greatly improves the accuracy rate of the transmission line galloping prediction, To form more precise and accurate dancing prediction results, it is convenient for the Power department to carry out the warning work of transmission line dancing at different time scales.

\section{Acknowledgements}

The research was financially supported by the National Grid Corporation Major foundation forward-looking technology project (SG20141187), and the support was gratefully acknowledged.

\section{References}

[1] Zhu Quanjun, Zhang Guowei, Shandongjie, et. Galloping control technology of overhead transmission lines in China [c]//impact of natural disasters on power facilities and Countermeasures seminar, Beijing, 2008: 360-370.

[2] ZHU Kuanjun, LIU Chaoqun, REN Xichun. Anti galloping of UHV transmission line [J]. High Voltage Technology, 2007, 33 (11): 61-65 (in Chinese).

[3] HU Hongchun. The prevention and control of ice damage, ice flashover and dancing [J]. Electric Power Construction, 2005, 26 (9): 31-33 (in Chinese).

[4] Zhou Lin. Numerical simulation and parametric analysis of ice-covered splitting conductor dancing [D]. Chongqing: Chongqing University, 2005.

[5] Luming Typical fault analysis of transmission line operation [M]. Beijing: China Power Press, 2014.

[6] Yao, Chen Min, Wang Jianjie. Application of variational assimilation in L-band minute data in WRF mode [J]. Meteorology, 2015, 41 (6): 695-706.

[7] Yang Lun Experimental study and nonlinear dynamics analysis of ice-covered transmission line dancing [D]. Hangzhou: Zhejiang University, 2014

[8] Chen Qiuping, Chen Ziqiang, Liu Jinxiu and so on. The early warning system of strong convection weather forecast using satellite and radar data [J]. Meteorological technology. 2012. 39 (5): 545-551.

[9] Wu Guorui. Li Shuqing. Feng Xiaojian. Rainstorm and strong convective weather early warning system [J]. Guangdong Meteorological. 2003. 4th: 29-30.

[10] Chen Deseng. A study on the relationship between Doppler weather radar and lightning early warning $[\mathrm{J}]$. Meteorology and environmental Science. 2010. 33 (1): 36-39.

[11] Li Shuai. Li Zhe. Liang. Application of strong convection early warning technology in power grid production $[\mathrm{J}]$. Henan Science and Technology. 2015. Under 9th: 149-152.

[12] Zhouning. Bear Xiao Volt. Power meteorological technology and application [M]. Beijing: China Electric Power Press. 2015. 1. 
[13] Shengliang, Yi Hui. Ice coating and protection of transmission lines [M]. China Electric Power Press, 2002.

[14] Pan Yingjie. Study on ice cover disaster early warning and emergency response system of overhead transmission line [D]. Yunnan University 2014.

[15] Zhang Lichun, Zhu Quanjun. Study on the Law of ice-covered dance disaster in transmission lines [J]. Power grids and clean energy. 2012 (09).

[16] Wang Jian. Study on risk analysis and early warning method of meteorological disaster in transmission line [D]. Chongqing University 2016.

[17] Sun Jianmao. Research on dance analysis and anti-dance technology of transmission line [D]. Zhejiang University 2010.
[18] Cao Jin Kam. Study on aerodynamic and dance characteristics of ice-covered conductors [D]. Huazhong 2013.

[19] Yong. Discussion on anti-icing disaster of transmission line [J]. Private science and technology. 2012 (12).

[20] Emad H. El-Zohri, M. Abdel-Salam, Hamdy M. Shafey, A. Ahmed. Mathematical modeling of flashover mechanism due to deposition of fire-produced soot particles on suspension insulators of a HVTL [J]. Electric Power Systems Research. 2013.

[21] Wang Shaohua, Shengliang, Sun Cai new. Research status of transmission line wire dance at home and abroad [J]. High voltage technology. 2005 (10). 